\title{
Differential absorption radar techniques: water vapor retrievals
}

\author{
Luis Millán, Matthew Lebsock, Nathaniel Livesey, and Simone Tanelli \\ Jet Propulsion Laboratory, California Institute of Technology, Pasadena, California, USA \\ Correspondence to: Luis Millán (lmillan@jpl.nasa.gov)
}

Received: 8 March 2016 - Published in Atmos. Meas. Tech. Discuss.: 22 March 2016

Revised: 26 May 2016 - Accepted: 30 May 2016 - Published: 21 June 2016

\begin{abstract}
Two radar pulses sent at different frequencies near the $183 \mathrm{GHz}$ water vapor line can be used to determine total column water vapor and water vapor profiles (within clouds or precipitation) exploiting the differential absorption on and off the line. We assess these water vapor measurements by applying a radar instrument simulator to CloudSat pixels and then running end-to-end retrieval simulations. These end-toend retrievals enable us to fully characterize not only the expected precision but also their potential biases, allowing us to select radar tones that maximize the water vapor signal minimizing potential errors due to spectral variations in the target extinction properties. A hypothetical CloudSat-like instrument with $500 \mathrm{~m}$ by $\sim 1 \mathrm{~km}$ vertical and horizontal resolution and a minimum detectable signal and radar precision of -30 and $0.16 \mathrm{dBZ}$, respectively, can estimate total column water vapor with an expected precision of around $0.03 \mathrm{~cm}$, with potential biases smaller than $0.26 \mathrm{~cm}$ most of the time, even under rainy conditions. The expected precision for water vapor profiles was found to be around $89 \%$ on average, with potential biases smaller than $77 \%$ most of the time when the profile is being retrieved close to surface but smaller than $38 \%$ above $3 \mathrm{~km}$. By using either horizontal or vertical averaging, the precision will improve vastly, with the measurements still retaining a considerably high vertical and/or horizontal resolution.
\end{abstract}

\section{Introduction}

The WMO (2014) statement of guidance for global numerical weather prediction concluded that one of the critical atmospheric variables that are not adequately measured by current or planned systems is humidity; in particular, profiles with adequate vertical resolution in cloudy areas were recommended (Anderson, 2014). Due to its importance, several spaceborne methods have been used to observe atmo- spheric water vapor, such as passive near-infrared or microwave imaging, passive infrared or microwave sounding, and radio occultation techniques. Most of these techniques have been shown to improve weather forecasting performance once assimilated (Anderson, 2007) and are operationally used, but each has limitations. For example, infrared and microwave sounders have broad weighting functions near the Earth's surface, which considerably limit their vertical resolution. Near-infrared and microwave imaging can only provide column water vapor, and hence they do not provide any information on its vertical distribution. Additionally, near-infrared and infrared techniques cannot penetrate cloudy scenes. Lastly, even though radio-occultation techniques are sensitive even to the boundary layer water vapor burden, atmospheric ducting effects associated with the top of the boundary layer limit their accuracy (Ao et al., 2003).

In this study we assess the differential absorption radar (DAR) concept to profile water vapor in cloudy and rainy areas. This technique is analogous to the differential absorption lidar (DIAL) technique (e.g., Schotland, 1966, Browell et al., 1979 and Wulfmeyer and Walther, 2001). The DAR concept exploits the difference between the radar reflectivity at different frequencies ("on" and "off" an absorption line) to estimate the absorbing gas path between the radar and the scattering target. The DAR technique can be used to retrieve surface pressure by estimating the column of oxygen using frequencies near the $60 \mathrm{GHz}$ absorption band (Flower and Peckham, 1978; Lin and $\mathrm{Hu}, 2005$; Lawrence et al., 2011; Millán et al., 2014). Prior studies show that this technique can be used to retrieve water vapor profiles using three frequencies centered around the $22 \mathrm{GHz}$ water vapor absorption line (Meneghini et al., 2005), frequencies at 10 and $94 \mathrm{GHz}$ (Tian et al., 2007), and at 2.8 and $35 \mathrm{GHz}$ (Ellis and Vivekanandan, 2010) using the water vapor continuum. In addition, Lebsock et al. (2015) assessed the feasibility of water vapor sounding using two frequencies at the wings of the $183 \mathrm{GHz}$ water 
vapor line using large eddy simulations (LES). These highresolution LES allowed the assessment of uncertainties due to small-scale heterogeneities within the radar field of view (commonly known as non-uniform beam filling) as well as uncertainties due to the particle size distribution. However they do not provide context on the capabilities of DAR over a wide variety of Earth's clouds. This global climatological context is best provided by observations. Following Lebsock et al. (2015) the study will focus on the wing of the $183 \mathrm{GHz}$ water vapor line, but we will evaluate the DAR capabilities using global cloud observations from CloudSat (Stephens et al., 2002). The water vapor line at $183 \mathrm{GHz}$ is used rather than the $22 \mathrm{GHz}$ because its attenuation is stronger which provides a greater dynamical range allowing us to explore cloud and rain profiling. We specifically focus on a spaceborne observational platform.

A spaceborne implementation of a water vapor DAR would provide observational capabilities that complement existing remote sensing methods. In particular the method specifically samples within the cloudy environment. This could provide much needed observations within the poorly sampled cloudy boundary layer and help constrain the relative humidity in ice clouds. Furthermore, the method can provide high spatial resolution column water vapor in all weather conditions and over all surfaces.

In this study we evaluate the ability of the DAR technique to retrieve water vapor with high vertical and horizontal resolutions under cloudy/rainy conditions and we diagnose which radar tones are better suited for sampling different altitude ranges. This paper is organized as follows: the measurement theory is described in Sect. 2, the radiometric model is described in Sect. 3, total column water vapor retrievals are discussed in Sect. 4, while Sect. 5 explores the profiling capabilities of this technique. Section 6 summarizes the results.

\section{Theoretical basis}

As shown by Lebsock et al. (2015), the ratio of two radar reflectivities, neglecting multiple scattering, can be expressed as

$$
\frac{Z\left(v_{1}, r\right)}{Z\left(\nu_{2}, r\right)}=\frac{\Upsilon^{2}\left(\nu_{1}, r\right) \eta\left(v_{1}, r\right) \lambda_{1}^{4}}{\Upsilon^{2}\left(\nu_{2}, r\right) \eta\left(\nu_{2}, r\right) \lambda_{2}^{4}} \frac{\left|K\left(\nu_{2}, r\right)\right|^{2}}{\left|K\left(\nu_{1}, r\right)\right|^{2}},
$$

where $v$ is a radar tone frequency, $\lambda$ is the wavelength of radiation, and $K(v, r)$ is the dielectric constant of the target. $\eta(\nu, r)$ represents the hydrometeors backscatter coefficients and $\Upsilon^{2}(v, r)$ is the two-way transmission along the range $r$ given by

$\Upsilon^{2}(\nu, r)=\exp \left(-2 \int_{0}^{r}\left[\sigma_{\text {gas }}(\nu, r)+\sigma_{\text {Pext }}(v, r)\right] \mathrm{d} r\right)$,

where $\sigma_{\text {gas }}(v, r)$ represents the gaseous absorption coefficient and $\sigma_{\text {Pext }}(\nu, r)$ the particulate extinction (the sum of

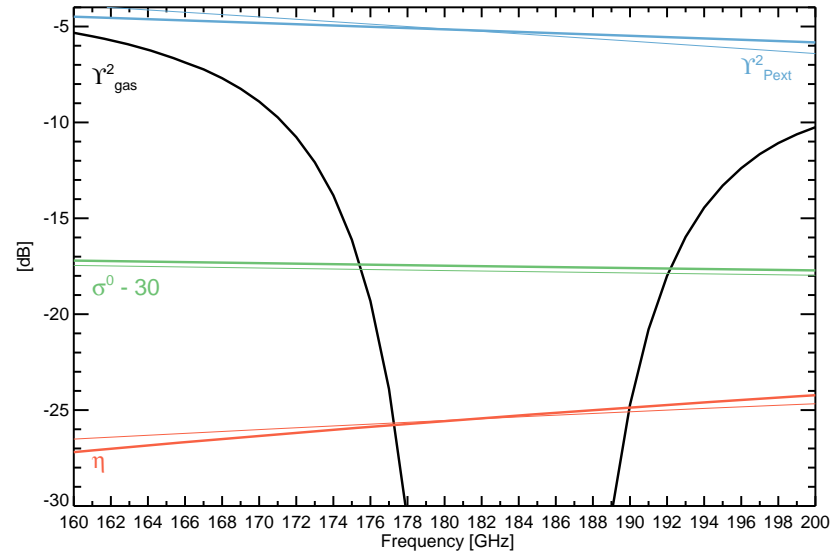

Figure 1. Example of a typical atmospheric transmittance due to gases $\left(\Upsilon_{\text {gas }}^{2}(\nu)\right.$, black) and hydrometeors $\left(\Upsilon_{\text {Pext }}^{2}(\nu)\right.$, blue $)$, as well as the backscatter reflectivity $(\eta(\nu)$, red), and the ocean backscatter $\left(\sigma_{0}^{2}(v)\right.$ green, offset by $\left.30 \mathrm{~dB}\right)$ for a surface return journey (downward atmospheric pass, surface reflection, upward pass) for a nim-

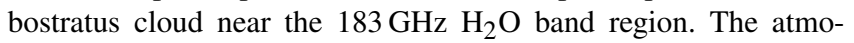
spheric profile was taken from CloudSat data as described in Sect. 3. The ocean backscatter corresponds to a surface wind of $3 \mathrm{~m} \mathrm{~s}^{-1}$ and temperature of $28^{\circ} \mathrm{C}$. Note that only the transmittance due to gases shows a significant frequency dependence. Thin lines show the impact of assuming a different particle size distribution or a different surface wind. These lines have been offset to ease comparison against the unperturbed ones.

absorption and scattering) coefficient. Note that in Eq. (1), when the scattering target is the surface rather that hydrometeors along the path, $\eta(\nu, r)$ is replaced by the normalized surface cross section $\sigma_{0}(v)$.

Assuming that these frequencies are chosen close to a strong absorption line, and the frequency dependence of $\sigma_{\text {Pext }}(\nu, r), \eta(v, r)$, and $\sigma_{0}(v)$ is small relative to that of $\sigma_{\text {gas }}(\nu, r)$ (see Fig. 1), Eq. (1) simply becomes

$$
\begin{aligned}
\frac{Z\left(\nu_{1}, r\right)}{Z\left(\nu_{2}, r\right)} & =\frac{\Upsilon^{2}\left(\nu_{1}, r\right)}{\Upsilon^{2}\left(\nu_{2}, r\right)} \\
& =\exp \left(-2 \int_{0}^{r}\left[\sigma_{\text {gas }}\left(v_{1}, r\right)-\sigma_{\text {gas }}\left(\nu_{2}, r\right)\right] \mathrm{d} r\right),
\end{aligned}
$$

which can be rewritten as

$$
\begin{aligned}
& \frac{Z\left(v_{1}, r\right)}{Z\left(v_{2}, r\right)} \\
& =\exp \left(-2 \int_{0}^{r} \rho(r) \sum_{i} v_{i}(r)\left[\kappa_{i}\left(v_{1}, r\right)-\kappa_{i}\left(v_{2}, r\right)\right] \mathrm{d} r\right),
\end{aligned}
$$

where $\rho(r)$ is the air density and the sum is over all the absorbers with monochromatic absorption coefficient $\kappa_{i}(v, r)$ and volume mixing ratio $v_{i}(r)$.

Furthermore, close to a strong absorption line, the monochromatic absorption coefficient for the rest of the ab- 
Table 1. Radar model specifics

\begin{tabular}{ll}
\hline Parameter & Detail \\
\hline Water dielectric properties & Liebe et al. (1991) \\
Ice dielectric properties & Hufford (1991) \\
Ice water content (IWC) PSD* & McFarquhar and Heymsfield (1997) \\
Liquid water content (LWC) PSD & Using a log normal distribution with a \\
& $10 \mu$ m mean radius and a 1.3 spread. \\
Rain PSD & Abel and Boutle (2012) \\
Snow PSD & Sekhon and Srivastava (1970) \\
Gas absorption & Read et al. (2004) \\
Radiation propagation & Hogan and Battaglia (2008); Hogan (2013) \\
Surface reflection & Li et al. (2005b) assuming a surface wind of $3 \mathrm{~ms}^{-1}$, \\
& sea surface temperature of $28^{\circ} \mathrm{C}$, a Fresnel fraction of 1, \\
& and zero salinity. \\
\hline
\end{tabular}

* particle size distribution

sorbers (at two close enough frequencies) are similar, leaving mostly the influence of the main absorber. For example, next to the $183 \mathrm{GHz} \mathrm{H}_{2} \mathrm{O}$ absorption line, Eq. (4) can be simplified as

$$
\begin{aligned}
& \frac{Z\left(v_{1}, r\right)}{Z\left(v_{2}, r\right)} \\
& =\exp \left(-2 \int_{0}^{r} \rho(r) v_{\mathrm{H}_{2} \mathrm{O}}(r)\left[\kappa_{\mathrm{H}_{2} \mathrm{O}}\left(v_{1}, r\right)-\kappa_{\mathrm{H}_{2} \mathrm{O}}\left(v_{2}, r\right)\right] \mathrm{d} r\right),
\end{aligned}
$$

which expressed in decibels relative to $Z$ units $(\mathrm{dBZ})$ and, using the ideal gas law, results in

$\mathrm{dBZ}\left(v_{1}, r\right)-\mathrm{dBZ}\left(v_{2}, r\right) \propto u_{\mathrm{H}_{2} \mathrm{O}}=\int_{0}^{r} \frac{p(r)}{R T(r)} v_{\mathrm{H}_{2} \mathrm{O}}(r) \mathrm{d} r$

where $R$ is the gas constant, $p$ is pressure, and $T$ is temperature.

Equation (6) shows that the difference between two radar tones expressed in $\mathrm{dBZ}$ units is proportional to the partial water vapor path $u_{\mathrm{H}_{2} \mathrm{O}}$ between the radar and the scattering target. This means that a range-gated radar may be used to estimate profiles of water vapor density inside cloudy or rainy profiles assuming a temperature and pressure profile (e.g., from reanalysis fields). Furthermore, this technique may be used to estimate the total column water vapor (CWV) using the surface returns. However, the proportionality given by Eq. (6) assumes that the absorption from other gases as well as the particulate extinction and backscattering coefficient between the two radar tones were similar which might not be true under certain hydrometeor burdens.

In this study, a range-gated radar system is simulated to explore the uncertainties in the estimates of total CWV as well as in the profiles of water vapor inside cloudy and rainy scenarios using a state-of-the-art radar forward model. This model is not based upon Eq. (6), but rather a more complete version of Eq. (1) that also includes multiple scattering. Through this model we assess the impact of spectral variation of the particulate extinction and the backscatter coefficient, the impact due to absorption of other gases, the impact of the temperature and pressure profiles assumed, the impact of the assumed hydrometeor particle size distribution, and the impact of the spectroscopy uncertainties, among others (see for example Fig. 1 thin lines).

\section{Radiometric model}

Radar returns were simulated using the same radiometric model as discussed in Millán et al. (2014). In short, radar reflectivities were computed using time-dependent two-stream approximation (Hogan and Battaglia, 2008), assuming spherical hydrometeors, evaluating the gaseous properties using the clear sky forward model for the EOS Microwave Limb Sounder (Read et al., 2004), and computing the surface reflection using a quasi-specular scattering model for the ocean surface. See Table 1 for more details. Note that even though all the simulations presented in this study used an ocean backscatter model, typical land surface back scattering coefficients are also weakly frequency-dependent, and hence, due to the differential nature of the technique, the results shown here can reasonably be expected to be similar to those found over land.

Throughout the study this radiometric model is run with a nadir viewing angle, to simulate radar tones close to the $183 \mathrm{GHz}$ absorption line, using CloudSat retrievals as inputs. In particular we use the liquid water content (LWC) and ice water content (IWC) profiles from the 2B-CWCRO R04 (Austin and Stephens, 2001; Austin et al., 2009) products, the rain and snow profiles from the 2C-RAINPROFILE (Lebsock and L'Ecuyer, 2011) products, and the temperature, pressure, water vapor, and ozone from the Euro- 


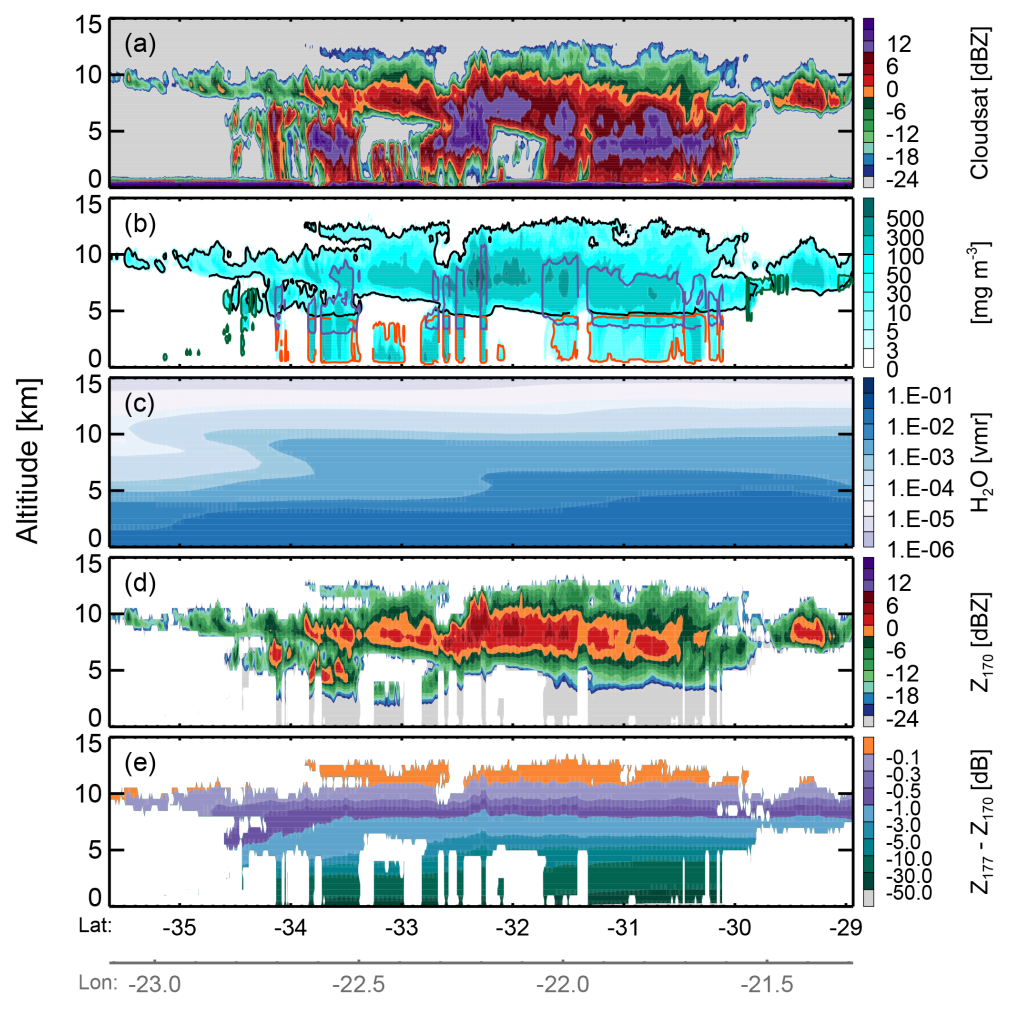

Figure 2. Cross section exemplifying the CloudSat-driven simulations (data from 15 January 2007 over the South Atlantic Ocean). (a) CloudSat radar reflectivity. (b) CloudSat retrieved total (IWC+LWC+rain+snow) hydrometeor water content. Black, green, red and purple lines, respectively, delimit areas where IWC, LWC, rain, and snow were present. (c) ECMWF-aux water vapor. (d) Simulated CloudSat-driven radar reflectivity at $170 \mathrm{GHz}$. (d) Simulated radar reflectivity difference $(177-170 \mathrm{GHz})$.

pean Centre for Medium-Range Weather Forecasts auxiliary (ECMWF-aux) products (Partain, 2007). The ECMWF-aux data are ECMWF weather analysis outputs interpolated in time and space to the CloudSat measurements. We also use the 2B-CLDCLASS product (Sassen and Wang, 2008) for cloud classification. Furthermore, we assume a radar with the same detectable signal (the radar sensitivity) and the same radar precision as CloudSat's Cloud Profiling Radar (Tanelli et al., 2008), that is to say -30 and $0.16 \mathrm{dBZ}$, respectively. We also assume a similar vertical ranging and horizontal sampling resolution: $500 \mathrm{~m}$ and around $1 \mathrm{~km}$, respectively. Viewing angles off the nadir, provided by using a scanning radar, are not explored in this study but, apart from the extra attenuation due to the longer paths, they are fundamentally the same as when using the nadir view.

As an example to illustrate the nature of the measurement, Fig. 2 shows a cross section of CloudSat-driven simulations over the South Atlantic Ocean. This cross section consists of 700 CloudSat profiles encompassing high thin cirrus, some liquid clouds, rain, and snow. As shown, the water vapor field not only decreases exponentially with height, it also shows a tongue that increases with height along the track, starting from around $32^{\circ} \mathrm{S}$ at $5 \mathrm{~km}$ and finishing at around $35.5^{\circ} \mathrm{S}$ and $10 \mathrm{~km}$. The impact of this water vapor burden can be seen in the simulated $170 \mathrm{GHz}$ radar reflectivity subplot; at this frequency, the radar signal has been considerably more attenuated than at $94 \mathrm{GHz}$ (the CloudSat radar tone, which was placed far away from any absorption line). Furthermore, the radar reflectivity difference $(177-170 \mathrm{GHz})$ already displays a resemblance to the water vapor field, for example the influence of the water vapor tongue around $10 \mathrm{~km}$ and $34.5^{\circ} \mathrm{S}$ can already be seen in the radar reflectivity difference.

Figure 3 illustrates the relationship between water vapor path and radar reflectivity difference using CloudSat-driven simulations. As predicted by Eq. (6) there should be a linear relationship between water vapor path and the radar reflectivity difference, either when the scattering target is the surface or hydrometeors. In the first instance, the radar reflectivity difference will be proportional to the total CWV, while in the latter it will be proportional to the partial CWV, the amount of water vapor above the scattering target. As shown, even under moderately rainy scenarios, the linear relationship is clearly apparent. The slope of these curves is the exploitable signal, which is on the order of $2.3 \mathrm{db} / 1 \mathrm{~cm}$ for this pair of radar tones, while the scatter may be interpreted as noise. Observe that under clear sky conditions a robust linear relationship is found between the total CWV and the surface return difference. The spread results from the different temper- 


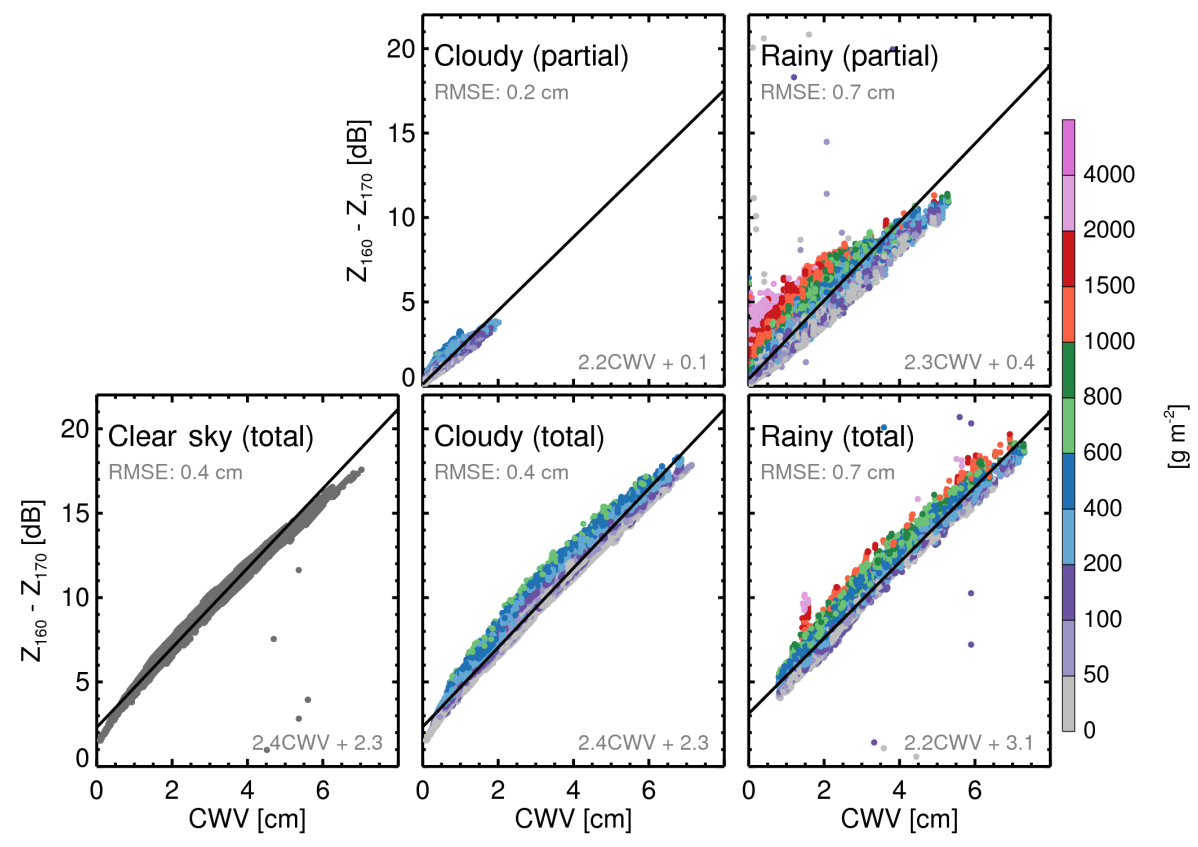

Figure 3. Simulated relationships between surface radar returns and total and partial CWV. Each point represents a CloudSat-driven simulation for each of the CloudSat measurements available from 15 January 2007. The total or partial hydrometeor column is color-coded. Dark gray is used for clear sky cases (total hydrometeor column equal to zero). The black line shows the linear regression. The root mean square error (RMSE) displayed is the overall linear regression error for each scenario. The top row shows the relationship between the range-gated radar returns and partial CWV and the bottom row displays the relationship between the surface returns and total CWV.

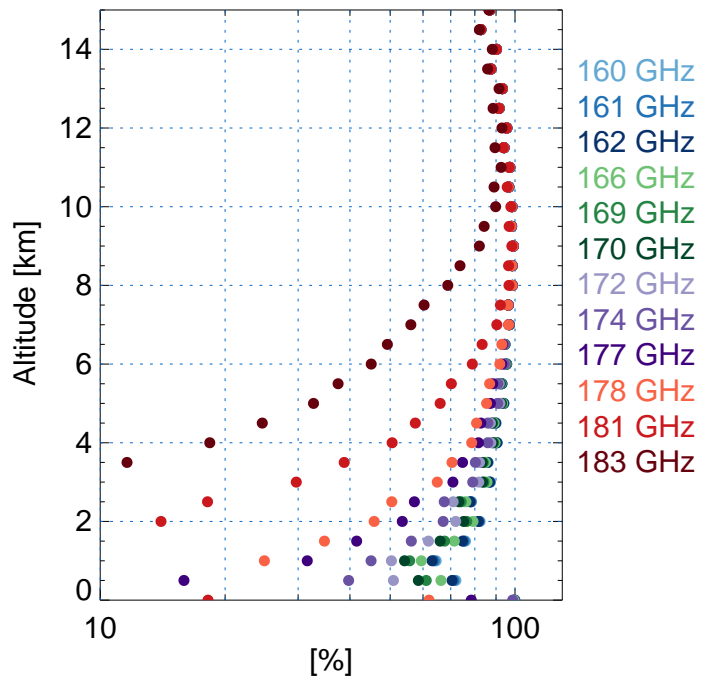

Figure 4. Percentage penetration for frequencies discussed in this study calculated using CloudSat-driven simulations for 10 days, assuming a radar sensitivity of $-30 \mathrm{dBZ}$.

ature and pressure profiles for the same water vapor burden. Under cloudy and rainy scenarios the spread also increases proportionally to the mass of condensate.

The root mean square errors (RMSEs) of these linear fits can be interpreted as the maximum likely precision error of a water vapor retrieval. The results are promising. They show that even without knowledge of the temperature, pressure and hydrometeor burden, partial and total CWV can be constrained to less than $0.5 \mathrm{~cm}$ under clear and cloudy scenarios, and to under $0.7 \mathrm{~cm}$ for rainy ones. Note that if the hydrometeor burden is known (for example using the rangegated information from the $160 \mathrm{GHz}$ radar tone), one could subset the data using this ancillary information to constrain the partial and total CWV better.

It is important to notice that as the attenuation provides the differential radar signal it will also limit the penetration depth. In other words, it will also determine which altitude range of the atmosphere can be sampled. Figure 3 used the $170-160 \mathrm{GHz}$ frequency pair suggested by Lebsock et al. (2015) to best maximize the signal for vapor profiling within the boundary layer. These frequencies were chosen in the wing of the $183 \mathrm{GHz}$ absorption line to be able to penetrate the large water vapor concentrations residing in the boundary layer. However, to maximize the signal at higher altitudes the required frequency pairs will need to be selected closer to the line center, despite not being able to penetrate all the way to the surface. Figure 4 shows the penetration percentage for frequencies used throughout this study computed using around one and a half million CloudSat pixels (the first 10 days of January 2007) and assuming a sensitivity of $-30 \mathrm{dBZ}$. As shown, frequencies higher than $177 \mathrm{GHz}$ are severely impacted by attenuation in the lowest 
Table 2. Systematic uncertainties perturbations ${ }^{\mathrm{a}}$.

\begin{tabular}{|c|c|c|}
\hline Perturbation & Amount & Comments \\
\hline Temperature & $3 \mathrm{~K}$ & $\begin{array}{l}\text { Calculated as the average of } 10 \\
\text { randomly perturbed profiles }\end{array}$ \\
\hline Pressure & $5 \%$ & $\begin{array}{l}\text { Calculated as the average of } 10 \\
\text { randomly perturbed profiles }\end{array}$ \\
\hline IWC error & $50 \%$ & - \\
\hline LWC error & $50 \%$ & - \\
\hline Rain error & $50 \%$ & - \\
\hline Snow error & $50 \%$ & - \\
\hline IWC PSD ${ }^{\mathrm{b}} 1$ & - & Heymsfield et al. (2002) \\
\hline IWC PSD2 & - & Donovan and van Lammeren (2002) \\
\hline LWC PSD1 & - & $\begin{array}{l}\text { Log-normal distribution with a } \\
6 \mu \mathrm{m} \text { mean radius and a } 1.5 \text { spread. }\end{array}$ \\
\hline Rain PSD1 & - & Marshall and Palmer (1948) \\
\hline Rain PSD2 & - & Willis (1984) \\
\hline Snow PSD1 & - & Gunn and Marshall (1958) \\
\hline Surface wind & $12 \mathrm{~ms}^{-1}$ & To characterize uncertainties in $\sigma_{0}(v)$ \\
\hline Line strength & $0.25 \%$ & Pickett (1998) \\
\hline Line width & $4 \%$ & Bauer et al. (1989), Goyette and DeLucia (1990) \\
\hline $\mathrm{H}_{2} \mathrm{O}$ continuum & $10 \%$ & Meshkov (2006) \\
\hline $\mathrm{N}_{2}$ and $\mathrm{O}_{2}$ continuum & $10 \%$ & Meshkov (2006) \\
\hline A prioric ${ }^{\mathrm{c}}$ & $20 \%$ & $\begin{array}{l}\text { Calculated as the average of } 10 \\
\text { randomly perturbed profiles }\end{array}$ \\
\hline
\end{tabular}

a For the unperturbed characteristics see Table 1.

b Particle size distribution.

c Only applied to profile retrievals.

few kilometers of the atmosphere. However, notice that the strong surface reflection is detectable $60 \%$ of the time even at $178 \mathrm{GHz}$. The strength of the surface reflection should enable retrievals of total $\mathrm{CWV}$ in a diverse range of environments, even where profiling is not possible.

\section{Total column water vapor results}

To properly explore the capability of this technique to estimate total CWV we have performed end-to-end retrievals. The retrieval algorithm used was a linear least-squares fit (see Appendix A for more information) which allow us to quantify both the expected precision and the systematic errors of the total CWV estimates using ancillary knowledge of temperature, pressure, and the hydrometeor profile. This retrieval does not use any a priori information; that is to say, we do not use any additional information to constrain these retrievals. The expected precision is determined by the random noise in the radar measurements propagated through the retrieval algorithm, while the systematic errors will arise from the uncertainties in the ancillary knowledge used, as well as from the spectroscopy uncertainties. These end-to-end retrievals assume knowledge of the hydrometeors' vertical distribution. This knowledge is assumed to come from an offline radar tone using CloudSat-like retrievals. The impact of attenuation on this radar tone/retrievals is not investigated here.
For a given scene, a perturbed set of radar measurements is generated for each systematic uncertainty and run through the retrieval algorithm. Each of the retrieved results is then compared to the retrieved total CWV for an unperturbed run to estimate the impact of such perturbation. A list of the perturbations used can be found in Table 2. Figure 5 (middle column) shows the systematic error characterization for three different scenarios using the 160 and $170 \mathrm{GHz}$ radar tones.

Employing this end-to-end retrieval framework allows us to search for an optimum pair of radar tones that will minimize the total error. For each scene, we simply run end-toend retrievals to explore a given frequency space and then we choose the best radar tone combination. To find globally optimized radar tones, we performed around 30 end-to-end retrievals for each scene type (clear sky, cirrus, altostratus, altocumulus, stratocumulus, cumulus, nimbostratus, drizzle, slight rain, and moderate rain) using all the possible frequencies combination between 160 and $183 \mathrm{GHz}$, every $1 \mathrm{GHz}$ step. These scenes were constructed from CloudSat representative profiles spread throughout 2007. The optimum radar tones are found in Table 3. To ensure that the radar tones can be use globally, we only used radar tones that were able to penetrate all the way to the surface at least $80 \%$ of the time for clear sky and cloudy scenes and at least $60 \%$ for rainy ones. For clear sky cases the chosen tones are separated as much as possible (14 GHz baseline) to maximize the signal 
Table 3. Optimum radar tones

\begin{tabular}{rrcccc}
\hline & $\begin{array}{r}\text { Scene } \\
\text { type }\end{array}$ & $\begin{array}{c}\text { Radar tones } \\
(\mathrm{GHz})\end{array}$ & Precision $^{\mathrm{a}}$ & $\begin{array}{c}\text { Potential bias }^{\mathrm{a}} \\
60 \% \text { of the time }\end{array}$ & $\begin{array}{c}\text { Potential bias }^{\mathrm{a}} \\
80 \% \text { of the time }\end{array}$ \\
\hline \multirow{3}{*}{ Total CWV $(\mathrm{cm})$} & $\begin{array}{r}\text { Clear sky } \\
\text { Cloudy }\end{array}$ & 160,174 & $0.01 \pm 0.001$ & 0.10 & 0.14 \\
& Rainy & 166,174 & $0.01 \pm 0.001$ & 0.10 & 0.14 \\
& $<9 \mathrm{~km}$ & 178,183 & $86 \pm 33$ & 20 & 0.26 \\
\hline \multirow{3}{*}{ Profile $\mathrm{H}_{2} \mathrm{O}(\%)$} & $6-12 \mathrm{~km}$ & 178,183 & $84 \pm 77$ & 13 & 26 \\
& $6-9 \mathrm{~km}$ & 178,181 & $93 \pm 83$ & 25 & 20 \\
& $3-6 \mathrm{~km}$ & 169,177 & $69 \pm 63$ & 48 & 37 \\
& $1-3 \mathrm{~km}$ & 162,172 & $87 \pm 64$ & 50 & 78 \\
& $0-1 \mathrm{~km}$ & 160,170 & $114 \pm 77$ & 29 & 70 \\
\hline
\end{tabular}

${ }^{\text {a }}$ Estimates computed using end-to-end retrievals for each of the CloudSat measurements available from 15 January 2007.

${ }^{b}$ Rain rates lower $10 \mathrm{mmh}^{-1}$.
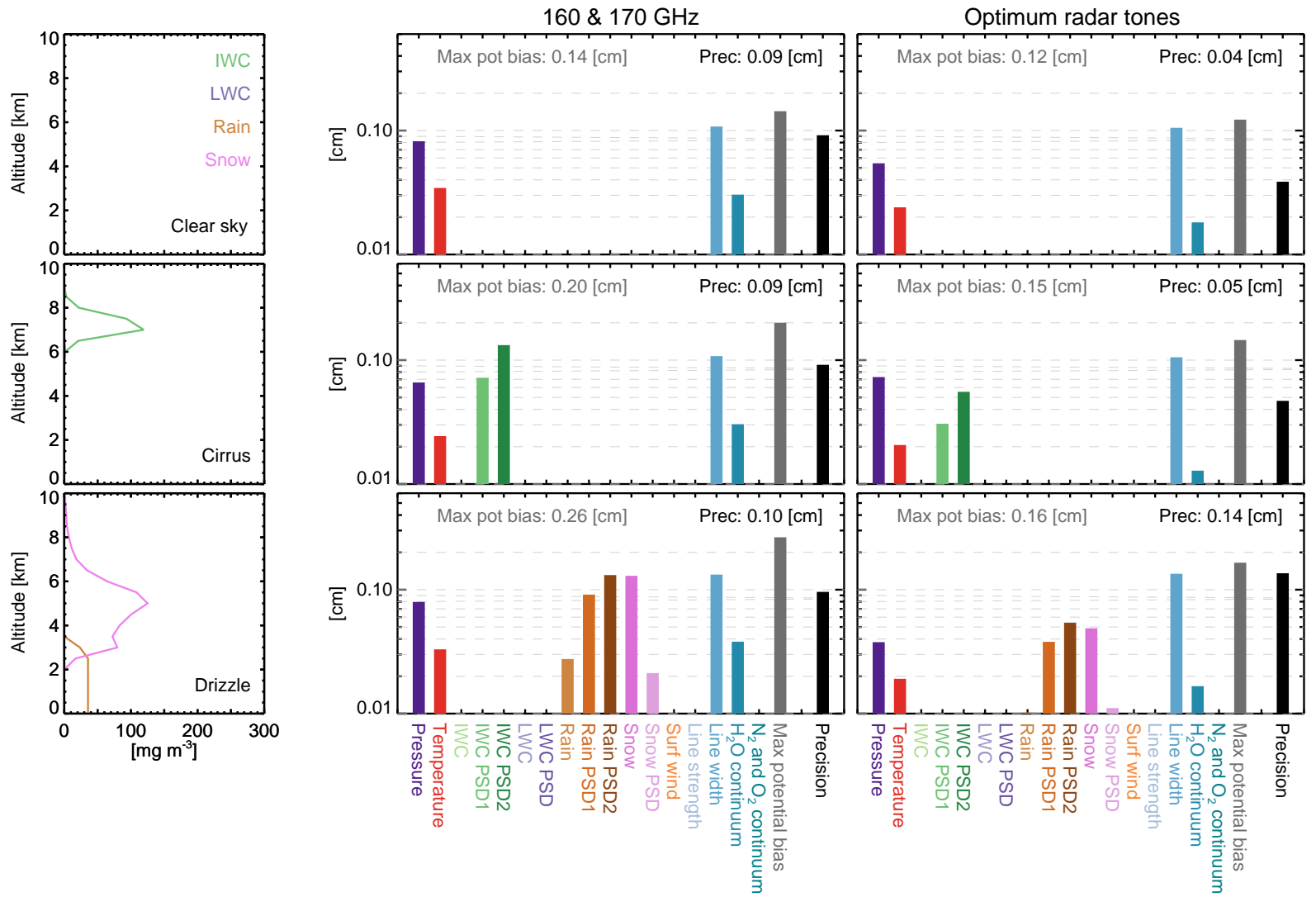

Figure 5. Systematic error estimates for total column water vapor retrievals caused by each of the sources described in Table 2 as well as the precision and maximum potential bias for three different scenarios (clear sky, cirrus, and drizzle). The maximum potential bias is the root-sum-square combination of all the systematic error sources. Left: hydrometeor burden for each of the scenarios; middle: simulations performed using 160 and $170 \mathrm{GHz}$ radar tones; right: simulation using optimum radar tones (see Table 3).

(i.e the attenuation in the on channel) and hence minimize the impact of the random noise. For rainy cases, the radar tones are close to each other (just $3 \mathrm{GHz}$ baseline) to minimize the impact of the uncertainties associated with the hydrometeors. Lastly, the cloudy cases sit in between these two extremes
( $8 \mathrm{GHz}$ baseline), trying to minimize both the precision and the systematic errors.

Note that these tones are optimal in the sense that they minimize the overall error; however there may be pairs of radar tones better suited for individual cases. Figure 5 (right 


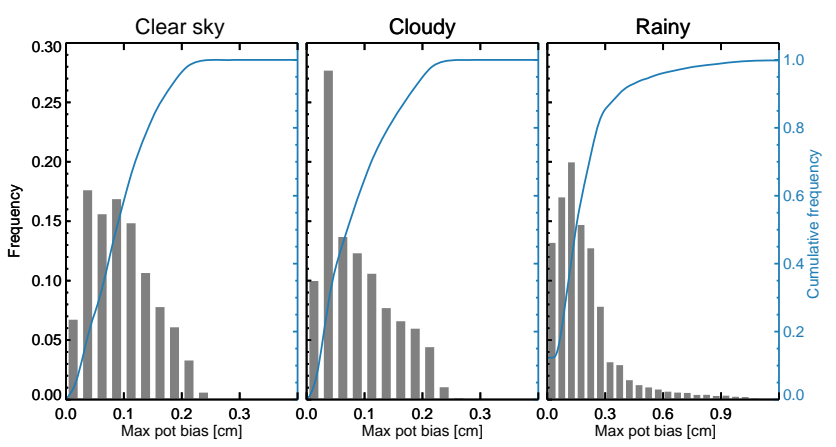

Figure 6. Histogram (gray) and cumulative histogram (blue) of the maximum potential biases for CloudSat-driven end-to-end total column water vapor retrievals for each of the CloudSat measurements available from 15 January 2007.

column) shows the impact of using the optimized radar tones. Overall, the precision has improved and the maximum potential biases (the root-sum-square combination of all the systematic error sources) have decreased compared to the results using the 160 and $170 \mathrm{GHz}$ radar tones. Observe that for the drizzle case, even though the precision has decreased, the optimum radar tones minimize the total error. In general, the most persistent potential bias is due to the water vapor line width uncertainty, followed by the assumed pressure profile. In cloudy and rainy situations this is followed by the hydrometeor error as well as their corresponding particle size distribution (PSD) uncertainties. Lastly, biases induced by uncertainties in temperature, surface wind, the background atmospheric absorption from $\mathrm{O}_{2}, \mathrm{~N}_{2}$, and $\mathrm{H}_{2} \mathrm{O}$ (i.e., the absorption continuum), as well as the water vapor line strength, are negligible.

To fully test the optimized radar tones, we have run endto-end retrieval simulations for CloudSat measurements from 15 January 2007 (more than 150000 pixels). Histograms and cumulative histograms of the maximum potential biases are shown in Fig. 6. Even under rainy conditions the expected precision was found to be $0.03 \mathrm{~cm}$ on average, with potential biases smaller than $0.26 \mathrm{~cm} 80 \%$ of the time. Table 3 lists the precision and potential biases for all weather conditions. This expected precision is half of the Advanced Microwave Scanning Radiometer (AMSR) expected total CWV precision reported by Wentz and Meissner (2000). The greater precision of DAR relative to the passive microwave results from the fact that DAR makes use of the stronger $183 \mathrm{GHz}$ line, whereas passive microwave relies on the $22 \mathrm{GHz}$ line.

Arguably to date, passive microwave instruments have provided the benchmark for CWV measurements. Not only might DAR total CWV have better precision but could also have a considerable better horizontal resolution, i.e., around $1 \mathrm{~km}$ rather than the native passive microwave footprint of $\sim 24 \mathrm{~km}$. Further, DAR total CWV estimates will be available over land and ocean rather that just over the oceans.

\section{Profiling capabilities}

As with total CWV, we have used end-to-end retrievals to further study the capabilities of this technique to estimate profiles of water vapor under cloudy and rainy scenarios. In this case, we have used an optimal estimation algorithm (Rodgers, 2000). This algorithm uses a priori data to constrain the retrieval. This additional information acts as an extra set of measurements and the solution can be thought as a weighted average between the measurements and the a priori. The a priori used is the mean profile of 100 adjacent CloudSat ECMWF-aux water vapor values smoothed by a boxcar average of four vertical levels. The uncertainties in this a priori are assumed to be $100 \%$, allowing the information to arise mostly from the simulated measurements. See Appendix B for more information.

Figure 7 exemplifies the profiling capabilities of this technique for a raining profile. As shown, different pairs of radar tones can sample different parts of the cloudy/rainy atmosphere: tones close to the line center can sample higher altitudes, while tones with moderate water vapor absorption can penetrate further into the surface. This can be appreciated in the averaging kernels subplots. These kernels delimitate the region of the atmosphere from which the atmospheric information is contributing to the retrieved values at a given altitude (Rodgers, 2000). Hence, if only two radar tones are going to be used, they will need to be carefully chosen to be able to sample the desired vertical region. In this study, altitudes where the kernel maximum is greater than 0.4 are considered to have retrievals not influenced too much by the a priori and therefore carry useful retrieved information. The expected precision and systematic errors are only shown for those altitudes. As shown in the last row of Fig. 7, it is possible to sample the entire vertical profile using multiple radar tones. Figure 8 shows the retrieved water vapor profiles over the same cross section displayed in Fig. 2c. As shown, this technique could provide valuable information for studies of water vapor vertical and horizontal distribution in cloudy/rainy areas and as input to weather forecasting models, complementing the existing water vapor measurements well. The use of multiple radar tones is analyzed here purely from an information content point of view with no concern for practical implementation matters.

Note that the tone pairs used in Figs. 7 and 8 are optimized for different vertical regions (except for the multi-tone retrievals). These radar tones were found using the same approach as for total CWV vapor. These optimum radar tones can be found in Table 3. If only two tones are available, to ensure that they can penetrate down to the lowest desired altitude, radar tones better suited for higher altitudes need to be sacrificed. As before, to test the applicability of these radar tones, we run end-to-end retrieval simulations for CloudSat measurements from the 15 January 2007. Histograms and cumulative histograms of the maximum potential biases are shown in Fig. 9. The expected precision was 

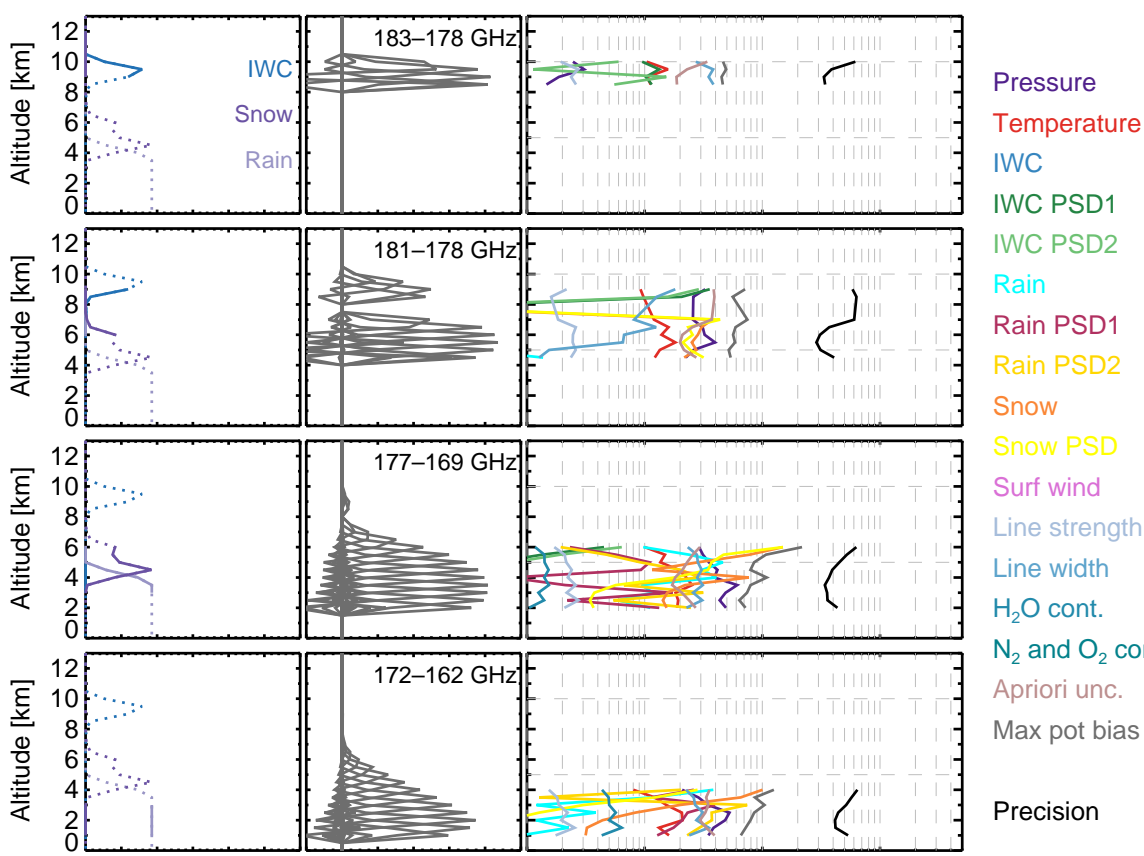

Surf wind

Line strength

Line width

$\mathrm{H}_{2} \mathrm{O}$ cont.

$\mathrm{N}_{2}$ and $\mathrm{O}_{2}$ cont.

Apriori unc.

Max pot bias

Precision
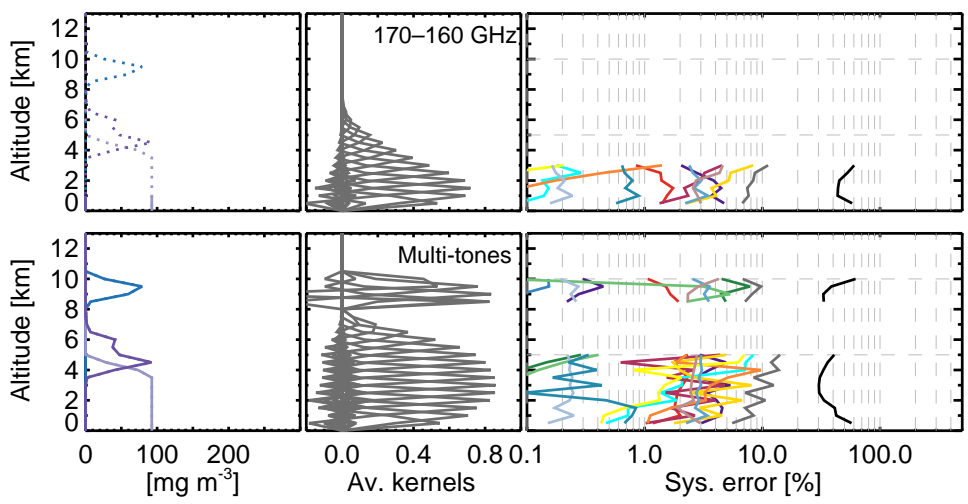

Figure 7. Left: color-coded hydrometeor burden. Dotted lines show the entire profile, while solid lines display the vertical range for which the radar tones used are better suited. Middle: averaging kernels. Right: systematic error estimates caused by each of the sources described in Table 2 as well as the precision and maximum potential bias. These errors are only shown for altitudes with kernels greater than 0.4, which indicates retrievals not influenced by the a priori. The top five rows show "optimized" radar tones for different vertical regions. The last row displays an example of how multi-tone $(183,177,170$, and $160 \mathrm{GHz}$ frequencies) retrievals can be used to sample an ample altitude range. Note that these multi-tone frequencies are not optimized.

found to be around $89 \%$ on average, with potential biases smaller than $\sim 80 \%$ when the profile is being retrieved close to surface but smaller than $37 \%$ above $6 \mathrm{~km} 80 \%$ of the time. At all altitude ranges, the main source of potential biases is the hydrometeor uncertainties, followed by pressure, temperature, and spectroscopic uncertainties. The last three contribute around $10 \%$ at most. We also notice that an a priori that is too dissimilar to the atmospheric profile has the potential to be a source of systematic uncertainty impacting more at higher altitudes.

At first glance, the DAR expected precision may seem large in comparison to uncertainties of current water vapor profilers. For example in the upper troposphere, the Mi- crowave Limb Sounder (MLS) (Waters et al., 2006) expected precision varies from 65 to $15 \%$ (Livesey et al., 2015), while the Atmospheric Infrared Sounder (AIRS) (Aumann et al., 2003) has uncertainty estimates of around $20 \%$ (Susskind et al., 2003). However, MLS has a $\sim 1.5$ to $3.0 \mathrm{~km}$ vertical resolution and a horizontal resolution of $7 \mathrm{~km}$ across track and $180 \mathrm{~km}$ along track (Livesey et al., 2015), while AIRS has a vertical resolution of around $2.7 \mathrm{~km}$ close to the surface and $4.3 \mathrm{~km}$ near the tropopause (Maddy and Barnet, 2008) with a field of regard of $\sim 40 \mathrm{~km}$. The potential resolution of DAR greatly exceeds the resolution of current water vapor profilers and, hence, the expected precision needs to be interpreted accordingly. For example, simply by matching their vertical 


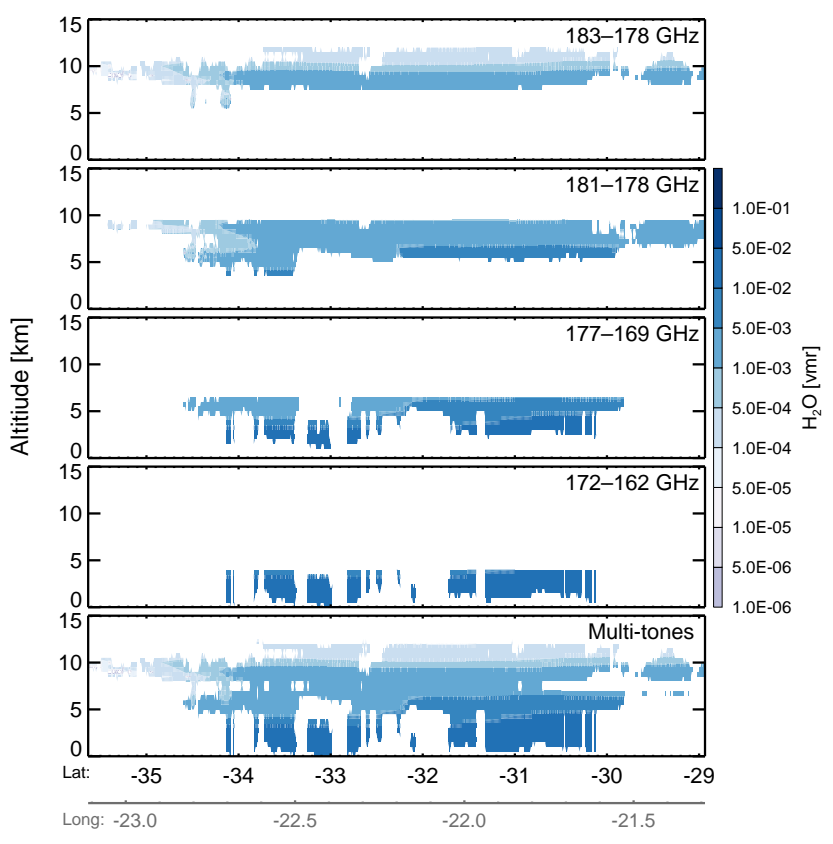

Figure 8. Cross section of CloudSat-driven water vapor retrievals. This is the same cross section as in Fig. 2c. Water vapor values are shown only for altitudes with kernels greater than 0.4 , which indicates retrievals not influenced by the a priori. The retrieved values using the 170-160 radar tone combination are not displayed because, as shown in Fig. 2b, there were no hydrometeors close to the surface.

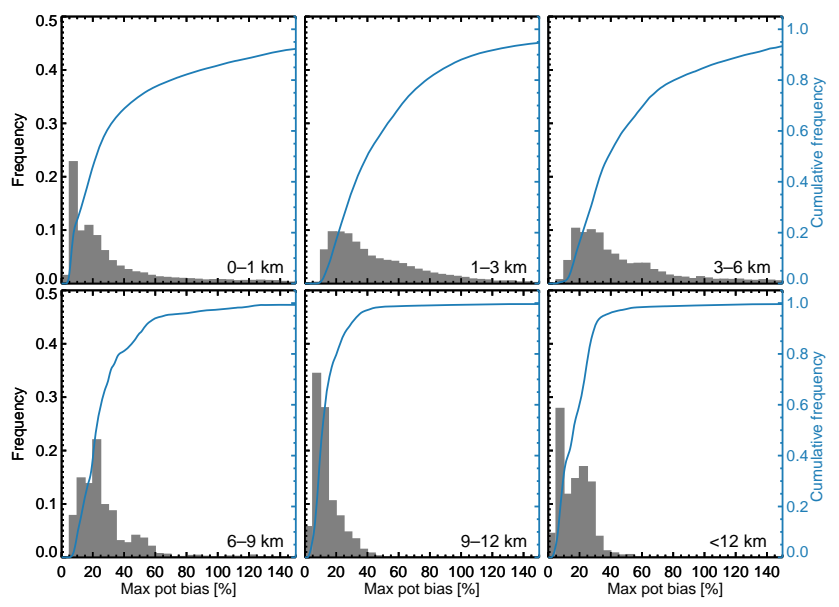

Figure 9. Histogram (gray) and cumulative histogram (blue) of the maximum potential biases for CloudSat-driven end-to-end profile water vapor retrievals for each of the CloudSat measurements available from 15 January 2007.

resolutions, the DAR precision could be improved by a factor of $\sim \sqrt{3}$ (when matching the $1.3 \mathrm{~km}$ MLS resolution) to $\sim \sqrt{8}$ (when matching the $\sim 4 \mathrm{~km}$ AIRS resolution), while still retaining the $\sim 1 \mathrm{~km}$ horizontal resolution.

\section{Conclusions}

We have discussed the theoretical capabilities of a differential absorption radar method to retrieve total column water vapor under clear sky, cloudy, and precipitating conditions, as well as water vapor profiles under cloudy and rainy conditions. This concept relies on radar reflectivities at two frequencies in the wings of the $183 \mathrm{GHz}$ water vapor line (on and off an absorption line) to estimate the absorbing gas path between the radar and the scatterer.

An inversion scheme was implemented, focusing on the retrieval propagation of measurement noise as well as systematic biases. This scheme provided a mathematical basis for the weighting of the water vapor signal against errors introduced by uncertainties in other parameters needed by the retrieval such as the assumed pressure and temperature vertical distribution, hydrometeor abundances, particle size distributions, as well as spectroscopic uncertainties. Then, this scheme was used to select pair of radar tones that maximize the water vapor signal and minimize the total error at different targeted altitude ranges. As expected, to sound close to the surface, the inversion scheme selected radar tones well into the wing of the $183 \mathrm{GHz}$ to be able penetrate the large water vapor concentrations residing in the boundary layer and radar tones closer to the line center to sound higher altitude ranges.

Assuming an instrument precision of $0.16 \mathrm{dBZ}$ and a radar sensitivity of $-30 \mathrm{dBZ}$ and a retrieved vertical resolution of $500 \mathrm{~m}$ against a $\sim 1.7 \mathrm{~km}$ footprint, we found that even under rainy conditions, the total column water vapor expected precision will be $0.03 \mathrm{~cm}$ on average, with potential biases smaller than $0.26 \mathrm{~cm} 80 \%$ of the time. This precision is half as good as that of passive microwave total column water vapor measurements, with the potential of considerably better horizontal resolution. Further, DAR total column water vapor estimates would be available over land and ocean and essentially all sky because, for the radar tones selected, the surface return is always above the radar sensitivity limit.

For water vapor profiles, the expected precision was found to be around $89 \%$ on average, with potential biases $80 \%$ of the time smaller than $77 \%$ when the profile is being retrieved close to surface but smaller than $38 \%$ above $3 \mathrm{~km}$. Simply by matching the vertical resolution of current humidity sounders, the DAR precision could be improved considerably, still retaining the high horizontal resolution. Furthermore, DAR specifically samples in cloud and rain, where existing sensors suffer large errors or simply cannot measure. At all altitude ranges, the main source of potential biases are the hydrometeor uncertainties, and any attempt to characterize an instrument should probably be coupled with an effort to characterize the hydrometeor particle size distributions better. These results demonstrate that this technique holds considerable potential as a method for retrieving water vapor profiles under realistic cloudy and precipitating scenarios. 


\section{Appendix A: Least squares}

In this study, the least-squares retrieval is used to estimate a total water vapor column, $w$. The measurement vector $\boldsymbol{y}$ is determined by the differences between surface radar returns at different frequencies; that is to say

$$
\begin{aligned}
\boldsymbol{y}= & {\left[\mathrm{dB} Z\left(v_{2}, r_{\mathrm{s}}\right)-\mathrm{dB} Z\left(v_{1}, r_{\mathrm{s}}\right),\right.} \\
& \left.\mathrm{dB} Z\left(v_{3}, r_{\mathrm{s}}\right)-\mathrm{dB} Z\left(v_{1}, r_{\mathrm{s}}\right), \ldots\right] .
\end{aligned}
$$

For completeness, we present the theory for multiple radar tones even though in Sect. 4 we only used a pair. The idea is to minimize the sum of the square differences - a leastsquares approach - between the measurement vector $\boldsymbol{y}$ and the simulated measurements, given by

$$
\begin{aligned}
\hat{\boldsymbol{y}}(\mathbf{x})= & {\left[\mathbf{F}_{v_{2}, r_{\mathrm{s}}}(\mathbf{x}, \mathbf{b})-\mathbf{F}_{v_{1}, r_{\mathrm{s}}}(\mathbf{x}, \mathbf{b}), \mathbf{F}_{v_{3}, r_{\mathrm{s}}}(\mathbf{x}, \mathbf{b})\right.} \\
& \left.-\mathbf{F}_{v_{1}, r_{\mathrm{s}}}(\mathbf{x}, \mathbf{b}), \ldots\right],
\end{aligned}
$$

where $\mathbf{F}$ is the forward model described in Sect. 3, $\mathbf{x}$ is a water vapor linearization profile, and $\mathbf{b}$ is known as the forward model parameter and contains additional terms needed by the forward model but which are not retrieved (such as profiles of temperature, pressure, ice water content, liquid water content, rain, snow). In these simulations any reflectivity below the radar sensitivity is set to missing.

The solution of such system may be found by minimizing the cost function:

$\chi^{2}=[\boldsymbol{y}-\hat{\boldsymbol{y}}(\mathbf{x})]^{T} \mathbf{S}_{y}^{-1}[\boldsymbol{y}-\hat{\boldsymbol{y}}(\mathbf{x})]$,

where $\mathbf{S}_{y}$ is the matrix describing the noise covariance of the measurements.

Following Rodgers (2000), the iterative least-squares fit solution is given by

$\left.w_{i+1}=w_{i}+\left[\mathbf{K}^{T} \mathbf{S}_{y}^{-1} \mathbf{K}\right]^{-1} \mathbf{K}^{T} \mathbf{S}_{y}^{-1}\left[\boldsymbol{y}-\hat{\boldsymbol{y}}(\mathbf{x})_{i}\right)\right]$,

where the total water vapor column, $w_{i}$, is computed by suitably integrating the vertical profile $\mathbf{x}_{i}$, and

$\mathbf{K}=\left.\frac{\partial \hat{\boldsymbol{y}}(\mathbf{x})}{\partial w}\right|_{\mathbf{x}=\mathbf{x}_{i}}$

is the Jacobian matrix evaluated by finite differences perturbing the entire profile by $1 \%$. Note that after each iteration $\mathbf{x}_{i+1}$ is computed following

$\mathbf{x}_{i+1}=\frac{w_{i+1}}{w_{i}} \mathbf{x}_{i}$.

This technique estimates the uncertainties (the precision) in the retrieved total column water vapor, $w$, according to

$\mathbf{S}_{w}=\left(\mathbf{K}^{T} \mathbf{S}_{y}^{-1} \mathbf{K}\right)^{-1}$,

where $\mathbf{S}_{w}$ is the covariance matrix of the estimated total column water $w_{i+1}$.
So, to test the total column water vapor retrieval four parameters are needed: (1) the measurements $\boldsymbol{y},(2)$ the initial guess $x_{0}$, (3) the forward model parameters $\mathbf{b}$, and (4) the measurement covariance matrix $\mathbf{S}_{y}$. The measurements are CloudSat-driven simulations. The initial guess, that is to say the water vapor profile used in the first iteration, is a climatological water profile. The forward model parameters needed are IWC, LWC, rain, snow, temperature, and pressure. All of them were taken from the CloudSat retrieval products. The hydrometeor PSDs used were listed in Table 1, which are the same ones employed to compute the synthetic measurements. Lastly, the measurement covariance matrix was assumed to be a diagonal matrix with the variances of the elements of the measurement vector; that is to say

$\sigma^{2}=\left(\sqrt{2 \delta_{Z}}\right)^{2}$,

where $\delta_{Z}$ is the radar precision, in this study assumed to be $0.16 \mathrm{dBZ}$, and the expression within the brackets is just the addition in quadrature of the uncorrelated radar tones' precision.

While finding the solution of the retrieval problem is the central part of operational retrieval algorithms, it is not the main focus of this study. This study quantifies the theoretical capabilities of such measurements, and therefore, the precision and accuracy of the solution $w$ reached by the iterative process. As already mentioned, the uncertainty in the retrieved state due to the measurement noise (the precision) is described by the diagonal elements of the covariance matrix $\mathbf{S}_{w}$. To compute the accuracy, the impacts of various sources of systematic uncertainties were investigated. These errors were estimated using end-to-end retrieval simulations. First, for each systematic error a perturbed set of measurements were generated and ran through the retrieval algorithm. These perturbed measurements were computed following

$\mathbf{y}^{\prime}=\mathbf{F}\left(\mathbf{x}_{\mathrm{T}}, \mathbf{b}^{\prime}\right)$,

where $\mathbf{x}_{\mathrm{T}}$ is the true water vapor state as provided by the CloudSat-ECMWF product, and where $\mathbf{b}^{\prime}$ is the perturbed forward model parameter. Note that in $\mathbf{b}^{\prime}$ only one of the parameters is perturbed at a time; for instance, when computing the systematic uncertainty related to temperature, only the temperature values are perturbed, while the rest (IWC, LWC, rain, snow, PSDs, etc) are left unperturbed. Then, the retrieval results using the perturbed measurements were compared to the retrieved values from an unperturbed run, i.e., where the measurements were

$\boldsymbol{y}=\mathbf{F}\left(\mathbf{x}_{\mathrm{T}}, \mathbf{b}\right)$

and the difference between the two was a measure of the impact of a given systematic error source. Table 2 summarizes the perturbation used. 


\section{Appendix B: Optimal estimation}

In this study, optimal estimation retrievals are used to estimate water vapor profiles, $\mathbf{x}$. In these retrievals the problem is ill-conditioned and to find a meaningful solution an a priori constraint is added to the retrieval problem. Each element in the measurement vector, also denoted by $\boldsymbol{y}$, is determined by

$$
\begin{aligned}
y_{j k}= & \frac{\mathrm{dB} Z\left(v_{2}, r_{k}\right)-\mathrm{dB} Z\left(\nu_{2}, z_{k-1}\right)}{\partial r} \\
& -\frac{\mathrm{dB} Z\left(v_{1}, r_{k}\right)-\mathrm{dB} Z\left(v_{1}, r_{k-1}\right)}{\partial r},
\end{aligned}
$$

where $j$ is the frequency counter (excluding the reference frequency), $k$ is the range gate counter, and $\partial r$ is the vertical resolution. In a similar manner, the elements of the forward model are given by

$$
\begin{aligned}
\hat{y}_{j k}= & \frac{\mathbf{F}_{v_{2}, r_{k}}(\mathbf{x}, \mathbf{b})-\mathbf{F}_{v_{2}, r_{k-1}}(\mathbf{x}, \mathbf{b})}{\partial r} \\
& -\frac{\mathbf{F}_{v_{1}, r_{k}}(\mathbf{x}, \mathbf{b})-\mathbf{F}_{v_{1}, r_{k-1}}(\mathbf{x}, \mathbf{b})}{\partial r} .
\end{aligned}
$$

The solution of such system may be found by minimizing the cost function:

$\chi^{2}=[\boldsymbol{y}-\hat{\boldsymbol{y}}(\mathbf{x})]^{T} \mathbf{S}_{y}^{-1}[\boldsymbol{y}-\hat{\boldsymbol{y}}(\mathbf{x})]+[\mathbf{x}-\mathbf{a}]^{T} \mathbf{S}_{a}^{-1}[\mathbf{x}-\mathbf{a}]$,

where $\mathbf{a}$ is the a priori estimate with covariance $\mathbf{S}_{a}$. As mention before, the a priori used is the mean profile of $100 \mathrm{ad}-$ jacent CloudSat ECMWF-aux water vapor values smoothed by a boxcar average of four vertical levels, and the uncertainties in this a priori are assumed to be $100 \%$. In this case, the diagonal elements of $S_{y}$ are given by

$\sigma^{2}=\left(\sqrt{4 \delta_{Z}} / \partial r\right)^{2}$

because each element in the measurement vector involves four reflectivity measurements.
Following Rodgers (2000), the iterative solution is given by

$$
\begin{aligned}
\mathbf{x}_{i+1}= & \mathbf{x}_{i}+\left[\mathbf{K}^{T} \mathbf{S}_{y}^{-1} \mathbf{K}+\mathbf{S}_{a}^{-1}\right]^{-1} \\
& \left\{\mathbf{K}^{T} \mathbf{S}_{y}^{-1}\left[\boldsymbol{y}-\hat{\boldsymbol{y}}\left(\mathbf{x}_{i}\right)\right]+\mathbf{S}_{a}^{-1}\left[a-x_{i}\right]\right\},
\end{aligned}
$$

where in this case, the Jacobian matrix is given by

$\mathbf{K}=\left.\frac{\partial \hat{\boldsymbol{y}}(\mathbf{x})}{\partial x}\right|_{\mathbf{x}=\mathbf{x}_{i}}$.

This technique gives an estimate of the precision in the water vapor profiles according to

$\mathbf{S}_{x}=\left(\mathbf{K}^{T} \mathbf{S}_{y}^{-1} \mathbf{K}+\mathbf{S}_{a}^{-1}\right)^{-1}$.

Another important quantity used to diagnose the retrieval performance is the averaging kernel matrix, given by

$A=\frac{\partial \mathbf{x}}{\partial \mathbf{x}_{\mathrm{T}}}=\left(\mathbf{K}^{T} \mathbf{S}_{y}^{-1} \mathbf{K}+\mathbf{S}_{a}^{-1}\right)^{-1} \mathbf{K}^{T} \mathbf{S}_{y}^{-1} \mathbf{K}$,

where $\mathbf{x}_{\mathrm{T}}$ is the true state of the atmosphere and $\mathbf{x}$ is the retrieved state obtained in the last iteration of Eq. (B5). The rows of this matrix are the averaging kernels and they map the true state into the retrieval space; that is to say, they describe how the elements of the true state influenced the retrieved state. The width of the kernel is a measure of retrieval resolution. 
Acknowledgements. The research described in this paper was carried out by the Jet Propulsion Laboratory, California Institute of Technology, under contract with the National Aeronautics and Space Administration.

Edited by: G. Vulpiani

\section{References}

Abel, S. J. and Boutle, I. A.: An improved representation of the raindrop size distribution for single-moment microphysics schemes, Q. J. Roy. Meteorol. Soc., 138, 2151-2162, 2012.

Anderson, E.: Statement of guidance for global numerical weather prediction (NWP), available at: https://www.wmo.int/pages/ prog/www/OSY/GOS-RRR.html (last access: 1 March 2016), 2014.

Anderson, E., Hólm, E., Bauer, P., Beljaars, A., Kelly, G. A., McNally, A. P., Simmons, A. J., Thépaut, J.-N., and Tompkins, A. M.: Analysis and forecast impact of the main humidity observing systems, Q. J. Roy.

Ao, C. O., Meehan, T. K., Hajj, G. A., Mannucci, A. J., and Beyerle, G.: Lower troposphere refractivity bias in GPS occultation retrievals, J. Geophys. Res., 108, 4577, doi:10.1029/2002JD003216, 2003. Meteorol. Soc., 133, 14731485, doi:10.1002/qj.112, 2007.

Aumann, H. H., Chahine, M. T., Gautier, C., Goldberg, M. D., Kalnay, E., McMillin, L. M., Revercomb, H., Rosenkranz, P. W., Smith, W. L., Staelin, D. H., Strow, L. L., and Susskind, J.: AIRS/AMSU/HSB on the Aqua mission: Design, science objectives, data products and processing system, IEEE T. Geosci. Remote, 41, 253-264, 2003.

Austin, R. T. and Stephens, G. L.: Retrieval of stratus cloud microphysical parameters using millimeter-wave radar and visible optical depth in preparation for CloudSat: 1. Algorithm formulation, J. Geophys. Res., 106, 28233-28242 doi:10.1029/2000JD000293, 2001.

Austin, R. T., Heymsfield, A. J. and Stephens, G. L.: Retrieval of ice cloud microphysical parameters using the CloudSat millimeterwave radar and temperature, J. Geophys. Res., 114, D00A23, doi:10.1029/2008JD010049, 2009.

Bauer, A., Godon, M., Kheddar, M., and Hartmann, J .M.: Temperature and perturber dependences of water vapor line-broadening. Experiments at $183 \mathrm{GHz}$; calculations below $1000 \mathrm{GHz}$, J. Quant. Spectrosc. Ra., 41, 49-54, doi:10.1016/00224073(89)90020-4, 1989.

Browell, E. V., Wilkerson, T. D., and McIlrath, T. J.: Water vapor differential absorption lidar development and evaluation, Appl. Opt., 18, 3474-3483, doi:10.1364/AO.18.003474, 1979.

Donovan, D. and Lammeren, A.: First ice cloud effective particle size parameterization based on combined Lidar and radar data, Geophys. Res. Lett., 29, 1006, doi:10.1029/2001GL013731, 2002.

Ellis, S. M. and Vivekanandan J.: Water vapor estimates using simultaneous dual-wavelength radar observations, Radio Sci., 45, RS5002, doi:10.1029/2009RS004280, 2010.

Flower, D. A. and Peckham, G. E.: A Microwave Pressure Sounder, JPL Publication 78-68, Caltech, Pasadena, CA, 1978.
Gao, R., Popp, P., Fahey, D., Marcy, T., Herman, R., Weinstock, E., Baumgardener, D., Garrett, T., Rosenlof, K., Thompson, T., Bui, P., Ridley, B., Wofsy, S., Toon, B., Tolbert, M., Kärcher, B., Peter, T., Hudson, P., Weinheimer, A., and Heymsfield, A.: Evidence That Nitric Acid Increases Relative Humidity in LowTemperature Cirrus Clouds, Science, 303, 516-520, 2004.

Goyette, T. M. and DeLucia, F. C.: The Pressure Broadening of the $3_{12} \rightarrow 2_{20}$ Transition of Water Between $80 \mathrm{~K}$ and $600 \mathrm{~K}$, J. Mol. Spectrosc., 143, 346-358, 1990.

Gunn, K. L. S. and Marshall, J. S.: The distribution with size of aggregate snowflakes, J. Meteorol., 15, 452-461, 1958.

Heymsfield, A., Bansemer, A., Field, P. R., Durden, S. L., Stith, J. L., Dye, J. E., Hall, W., and Grainger, C. A.: Observations and parameterizations of particle size distributions in deep tropical cirrus and stratiform precipitating clouds: results from in situ observations in TRMM field campaigns, J. Atmos. Sci., 59, 3457-3491, 2002.

Hogan, R. J.: Multiscatter: a fast, approximate multiple scattering algorithm, University of Reading, Reading, UK, available at; http://www.met.reading.ac.uk/clouds/multiscatter/, last access: March 2013.

Hogan, R. J. and Battaglia, A.: Fast lidar and radar multiplescattering models, Part II: Wide-angle scattering using the timedependent two-stream approximation, J. Atmos. Sci., 65, 36363651, doi:10.1175/2008JAS2643.1, 2008.

Hufford, G. A.: A model for the complex permittivity of ice at frequencies below $1 \mathrm{THz}$, Int. J. Infrared Milli., 12, 677-682, 1991.

Lawrence, R. Lin, B., Harrah, S., Hu, Y., Hunt, P., and Lipp, C.: Initial flight test results of differential absorption barometric radar for remote sensing of sea surface air pressure, J. Quant. Spectrosc. Ra., 12, 247-253, 2011.

Lebsock, M. and L'Ecuyer, T. S.: The retrieval of warm rain from CloudSat, J. Geophys. Res., 116, D20209, doi:10.1029/2011JD016076, 2011.

Lebsock, M. D., Suzuki, K., Millán, L. F., and Kalmus, P. M.: The feasibility of water vapor sounding of the cloudy boundary layer using a differential absorption radar technique, Atmos. Meas. Tech., 8, 3631-3645, doi:10.5194/amt-8-3631-2015, 2015.

Li, L., Heymsfield, G. H., Tian, L., and Racette, P. E.: Measurements of ocean surface backscattering using an airborne 94-GHz cloud radar - implication for calibration of airborne and spaceborne W-Band radars, J. Atmos. Ocean. Tech., 22, 1033-1045, doi:10.1175/JTECH1722.1, 2005.

Liebe, H. J., Hufford, G. A., and Manabe, T.: A model for the complex permittivity of water at frequencies below $1 \mathrm{THz}$, Int. J. Infrared Milli., 12, 659-675, 1991.

Lin, B. and Hu, Y.: Numerical simulations of radar surface air pressure measurements at $\mathrm{O}_{2}$ bands, IEEE T. Geosci. Remote, 2, 324-328, 2005.

Livesey, N., Read, W. G., Wagner, P. A., Frovideaux, L., Lambert, A., Manney, G. L., Millán, L., Pumphrey, H. C., Santee, M. L., Schwartz, M. J., Wang, S., Fuller, R. A., Jarnot, R. F., Knosp, B. W., and Martinez, E.: Earth Observing System (EOS) Aura Microwave Limb Sounder (MLS) Version 4.2x Level 2 data quality and description document, JPL D-33509 Rev. A, JPL publication, Pasadena, CA, USA, 2015.

Maddy, E. S. and Barnet, C. D.: Vertical Resolution Estimates in Version 5 of AIRS Operational Retrievals, IEEE T. Geosci. Remote, 46, 2375-2384, doi:10.1109/TGRS.2008.917498, 2008 
Marshall, J. S. and Palmer, W. Mc K.: The distribution of raindrops with size, J. Meteorol., 5, 165-166, 1948.

McFarquhar, G. M. and Heymsfield, A. J.: Parameterization of tropical cirrus ice crystal size distribution and implications for radiatiave transfer: results from CEPEX, J. Atmos. Sci., 54, 21872200, 1997.

Meneghini, R., Liao, L., and Tian L.: A Feasibility Study for Simultaneous Estimates of Water Vapor and Precipitation Parameters Using a Three-Frequency Radar, J. Appl. Meteorol., 44, 15111525, doi:10.1175/JAM2302.1, 2005.

Meshkov, A. I.: Broadband Absolute Absorption Measurements of Atmospheric Continua with Millimeter Wave Cavity Ringdown Spectroscopy, PhD. Thesis, Ohio State Univ., Columbus, OH, USA, 2006.

Millán, L., Lebsock, M., Livesey, N., Tanelli, S., and Stephens, G.: Differential absorption radar techniques: surface pressure, Atmos. Meas. Tech., 7, 3959-3970, doi:10.5194/amt-7-3959-2014, 2014.

Partain, P.: CloudSat ECMWF-AUX Auxiliary Data Process Description and Interface Control Document, Cooperative Institute for Research in the Atmosphere, Colorado State University, Fort Collins, CO, 2007.

Pickett, H. M., Poynter, R. L., Cohen, E. A., Delitsky, M. L., Pearson, J. C., and Muller, H. S. P.: Submillimeter, millimeter, and microwave spectral line catalog, J. Quant. Spectrosc. Ra., 60, 883-890, 1998.

Read, W. G., Shippony, Z., and Snyder, W. V.: EOS MLS Forward Model Algorithm Theoretical Basis Document, Jet Propulsion Lab., JPL D-18130/CL\#04-2238, Pasadena, CA, USA, 2004.

Rodgers, C.: Inverse Methods for Atmospheric Sounding: Theory and Practice, Series on Atmospheric, Oceanic and Planetary Physics, Vol. 2, World Scientific, Singapore, 2000.

Sassen, K. and Wang, Z.: Classifying clouds around the globe with the CloudSat radar: 1-year of results, Geophys. Res. Lett., 35, L04805, doi:10.1029/2007GL032591, 2008.

Schotland, R. M.: Some observations of the vertical profile of water vapor by means of a ground based optical radar, Proceedings of the Fourth Symposium on Remote Sensing of the Environment, Environmental Research Institute of Michigan, Ann Arbor, MI, USA, 273-283, 1966.

Sekhon, R. S. and Sirvastava, R. C.: Snow size spectra and radar reflectivity, J. Atmos. Sci., 37, 299-307, 1970.
Stephens, G. L., Vane, D. G., Boain, R. J., Mace, G. G., Sassen, K., Wang, Z., Illingworth, A. J., O'Connor, E. J., Rossow, W. B., Durden, S. L., Miller, S. D., Austin, R. T., Benedetti, A., Mitrescu, C., and the CloudSat Science Team: The CloudSat mission and the A-train a new dimension of space-based observations of clouds and precipitation, B. Am. Meteorol. Soc., 83, 1771-1790, 2002.

Susskind, J., Barnet, C., and Blaisdell, J.: Retrieval of atmospheric and surface parameters from AIRS/AMSU/HSB data under cloudy conditions, IEEE T. Geosci. Remote, 41, 390-409, 2003.

Tanelli, S., Durden, S. L., Im, E., Pak, K. S., Reinke, D. G., Partain, P., Hyanes, J. M., and Marchand, R. T.: CloudSat's cloud profiling radar after two years in orbit: performance, calibration, and processing, IEEE Geosci. Remote S., 46, 3560-3573, 2008.

Tian, L., Heymsfield, G. M., Li, L., and Srivastava R. C.: Properties of light stratiform rain derived from 10- and 94-GHz airborne Doppler radars measurements, J. Geophys. Res., 112, D11211, doi:10.1029/2006JD008144, 2007.

Waters, J., Froidevaux, L., Harwood, R., Jarnot, R., Pickett, H., Read, W., Siegel, P., Cofield, R., Filipiak, M., Flower, D., Holden, J., Lau, G., Livesey, N., Manney, G., Pumphrey, H., Santee, M., Wu, D., Cuddy, D., Lay, R., Loo, M., Perun, V., Schwartz, M., Stek, P., Thurstans, R., Boyles, M., Chandra, S., Chavez, M., Chen, G.-S., Chudasama, B., Dodge, R., Fuller, R., Girard, M., Jiang, J., Jiang, Y., Knosp, B., LaBelle, R., Lam, J., Lee, K., Miller, D., Oswald, J., Patel, N., Pukala, D., Quintero, O., Scaff, D., Snyder, W., Tope, M., Wagner, P., and Walch, M.: The Earth Observing System Microwave Limb Sounder (EOS MLS) on the Aura satellite, IEEE T. Geosci. Remote., 44, 1075-1092, doi:10.1109/TGRS.2006.873771, 2006.

Wentz, F. J. and T. Meissner: AMSR ocean algorithm, version 2. Remote Sensing Systems Tech. Rep. 121599A-1, 66 pp., available at: http://eospso.gsfc.nasa.gov/sites/default/files/atbd/ atbd-amsr-ocean.pdf (last access: 1 March 2016), 2000

Willis, P. T.: Functional fits to some observed drop size distributions and parameterization of rain, J. Atmos. Sci., 41, 16481661, 1984.

Wulfmeyer, V. and Walther, C.: Future performance of groundbased and airborne water-vapor differential absorption lidar. I. Overview and theory, Appl. Optics, 40, 5304-5320, 2001. 